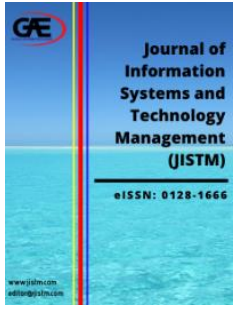

\author{
JOURNAL OF INFORMATION \\ SYSTEM AND TECHNOLOGY \\ MANAGEMENT (JISTM)

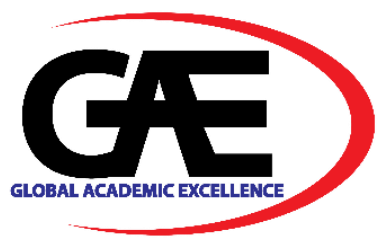

\title{
REVIEW OF INTERNATIONAL GNSS DATA SHARING POLICY FRAMEWORKS AND PRACTICES
}

\author{
Ooi Wei Han ${ }^{1 *}$, Tajul Ariffin Musa ${ }^{2}$, Wan Anom Wan Aris ${ }^{3}$ \\ 1 Faculty of Built Environment and Surveying, Universiti Teknologi Malaysia, Malaysia \\ Email: ooiweihan@gmail.com \\ 2 Faculty of Built Environment and Surveying, Universiti Teknologi Malaysia, Malaysia \\ Email: tajulariffin@utm.my \\ 3 Faculty of Built Environment and Surveying, Universiti Teknologi Malaysia, Malaysia \\ Email:wananom@utm.my \\ * Corresponding Author
}

\section{Article Info:}

\section{Article history:}

Received date: 01.10 .2021

Revised date: 01.11 .2021

Accepted date: 20.11.2021

Published date: 01.12.2021

To cite this document:

Ooi, W. H., Musa, T. A., \& Aris, W. A. W. (2021). Review Of International GNSS Data Sharing Policy Frameworks And Practices. Journal of Information System and Technology Management, 6 (24), 254-264.

DOI: $10.35631 / J I S T M .624024$

This work is licensed under $\mathrm{CC}$ BY 4.0

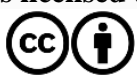

Abstract:

Global Navigation Satellite Systems, or GNSS, is a space technology that has become an important component of positioning, navigation, and timing (PNT) in a broad variety of military and civilian applications. Accordingly, the GNSS is being supported with Continuously Operating Reference Station (CORS) networks which are a common type of GNSS ground-based augmentation infrastructure that governments and industry use to distribute centimetre accurate PNT information throughout the nation or region. In Malaysia, there are few CORS networks currently in services. It was difficult to integrate CORS networks even within the country since the CORS operating came from several different organizations. Furthermore, the CORS data sharing between the public and private sectors in providing precise positioning applications also challenging issue due to the fact that the data contains sensitive information. The relevant policy document on data sharing in the country is still vague. This paper review on existing GNSS data sharing policy framework and practice at the international and national levels. A number of countries from each continents were chosen to be studied further in order to identify the requirements that could be considered for adoption. The goal of this study is to create a clear conceptual framework for GNSS data sharing in the country, as well as to resolve some grey areas between public and private GNSS users.

Keywords:

GNSS, CORS, Policy Framework, Data Sharing 


\section{Introduction}

Global Navigation Satellite Systems or GNSS is a space technology that has become essential element nowadays for positioning, navigation \& timing (PNT) with wide range of applications such as land and marine transportation, aviation, tracking, geo-engineering works, earth monitoring, and many more. The increasing dependence on GNSS is globally recognized, and some of the country even developing their own global navigation systems, namely Global Positing System (GPS) operated by United States of America; the Russian Globalnaya Navigazionnaya Sputnikovaya Sistema (GLONASS), the China's BeiDou Navigation Satellite System (BDS) and the EU's Galileo Satellite Navigation System (GALILEO). The GNSS industry started to invest in the development of new system and applications especially the mobile apps. There are now billions of PNT units in operation around the world and the new hardware and software designs promise smaller, cheaper and more capable GNSS receivers that can serve a wider range of user markets.

Apart from that, satellite augmentation systems are also being developed to support precise point positioning and real time applications. The Continuously Operating Reference Station (CORS) networks are a common form of ground-based augmentation infrastructure that governments and industry use to distribute centimeter accurate PNT information across the region. CORS networks have been deployed locally, nationally and globally to meet the scientific and commercial demands from multiple sectors. The operational models of the CORS network differed across countries, ranging from government organizations playing all roles, to a mixture of government and private sector or to large private networks.

In Malaysia, there are currently a few CORS networks that serve a variety of local needs. There are run by various government agency, university and industry, such as MyRTKnet, MSKDGPS, National R\&D CORS (NRC-net) and CORS by Land and Survey Sabah and Sarawak. Many local users are using the data to improve the accuracy of their work relevant to positioning and navigation. Although within the nation, integrating all the CORS networks was difficult since the CORS operating came from variety of organizations. Furthermore, the CORS data sharing between the public and private sectors in providing precise positioning applications also challenging issue due to the fact that the data contains sensitive information. At the moment, there are only a few documented policies and acts related to GNSS in place, and those policy documents on data sharing is unclear.

This paper review on existing GNSS data sharing policy framework and practice at the international and national levels. Further analysis will be conducted to identify the requirements that could be considered for adoption. This study is intended to propose a model of conceptual framework on GNSS data sharing in the country. It is important for policy makers involved in forming new arrangements for long-term sustainability development in GNSS data for the country.

\section{International Practice}

Most countries have developed almost a similar way when it comes to establishing CORS infrastructure to enable the use of data for civil, scientific, and commercial purposes. The model and practice for operating CORS differ by country. Some data is shared and licensed to industry to develop positioning services, while others are not. A few countries from each continent (North America, Europe, Asia, Oceania, and Africa) were chosen to further analysis. 


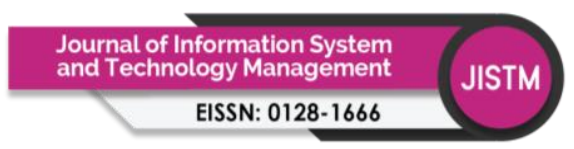

Volume 6 Issue 24 (December 2021) PP. 254-264 DOI: 10.35631/JISTM.624024

\section{Continent of America}

In United States, there is no government or industry service provider has established a high accuracy positioning service with national coverage. The National Geodetic Survey (NGS) within the National Oceanic and Atmospheric Administration (NOAA) is responsible for managing Federal government CORS and other infrastructure (NGS, 2013). The role of NGS is equivalent in providing the geodetic framework for all national positioning activities. This agency coordinates access to over 1800 multi-purpose CORS sites around the country that are contributed cooperatively by government, research and private data custodian. Each organization shares their data to NGS, which to analyse and monitors the data and make available to the public for post-processing purposes.

Meanwhile, the industry service providers have begun networking positioning services such as SmartNet North America adopts a licensing model to network approximately 600 CORS across the area, where the data has been licensed from government and privately own CORS. Data licensing model enables multiple service providers to access the same CORS infrastructure which improves the consistency of their computed PNT information. From an economy perspective, coordinating access to a CORS single station is cost-efficient for any operator rather than installing many CORS at the same place. User able to benefit from a more stable and dense network

\section{Continent of Europe}

The EUREF Permanent Network (EPN) is a CORS that has been installed across the European continent. The primary goal is to provide access to the European Terrestrial Reference System 89 (ETRS89), which is the EU's standard precise GNSS coordinate system. All contributions to the EPN are provided on a voluntary basis, with more than 100 European agencies and universities involved. The EPN Central Bureau which managed by the Royal Observatory of Belgium (ROB), performs the day-to-day EPN coordination and acts as liaison between station operators, data and analysis centers, and maintains the EPN Information System (Bruyninx, 2019). The RINEX data from the EPN stations are freely available through FTP from two regional data centers located at BKG, Germany and BEV, Austria and one historical data center, managed by the EPN Central Bureau at ROB. Meanwhile, the Real-time EPN data are distributed through three regional NTRIP broadcasters located at Italian Space Agency, BKG, and ROB.

Meanwhile, the INSPIRE is a Directive that imposes binding rules for the establishment of a spatial data infrastructure in the EU. The Implementing rules describe in full detail how various components of the infrastructure would operate. Metadata, data interoperability, network services and data sharing are all covered by these implementing rules. INSPIRE Directive requires that Member State's authorities to share data among themselves as well as with EU institutions under harmonized conditions, as outlined in the implementing rule for "data sharing" (Mikael. L, 2017).

\section{United Kingdom}

In United Kingdom, the CORS network is managed centrally by a single geodetic agency. The National Mapping Authority or Ordnance Survey, is responsible for creating, maintaining, and disseminating geospatial data as well as managing the national geospatial reference system. Apart from managing over 100 CORS infrastructures for their OS Net services, Ordnance Survey has partnership with commercial service providers, such as Leica Geosystem's 
SmartNet (UK and Ireland), Trimble's VRS Now, Topcon Positioning System's TopNetPlus, AXIO-NET's FarmRTK, and Soil Essential's Essentials Net to deliver positioning services (Ordnance Survey, 2013). Ordnance Survey is a data custodian that licenses access to OS Net's raw data streams, which are processed and distributed by service provider in the commercial market. In exchange for licensing access to its raw data streams, OS Net has partnered with a service provider to gain access to correction data for monitoring the national geospatial reference system. The OS Net also makes its online RINEX archive available and sharing with public users.

\section{Germany}

The Satellite Positioning Service (SAPOS) of the German Surveying and Mapping Authority integrates a uniform national network at approximately 270 CORS to establish the country's national geospatial reference system. The CORS are owned and managed by state government in each jurisdiction. SAPOS is a joint project of the Working committee of the Surveying Authorities of the States and Federal Republic of Germany (AdV). It operates on a fee-based commercial business model, with three positioning services available to the users. Likes the practice in UK, a license has been granted to the industry service provider to access SAPOS data in order to distribute value-added positioning services throughout Germany.

\section{Sweden}

Sweden was one of the earlier countries to use GPS for navigation, surveying and mapping. Lantmäteriet, the Swedish mapping, cadastral and land registry authority, to operate the national CORS network, known as SWEPOS, and in charge of geodata coordination across the country. The Department of Geodesy at Lantmäteriet is a major player in Sweden's geodetic field. Aside from managing the Swedish reference networks, the department also engages in extensive development, research, and support activities relevant to SWEPOS. The network currently has around 300 stations, which are all connected to a control center that has real-time access to GNSS data from all of the stations (Mikael L et. al, 2014).

\section{Continent of Oceania}

\section{New Zealand}

In New Zealand, the Land Information New Zealand (LINZ), a government department in partnership with GNS Science, through the GeoNet project, collects GNSS data from a network of 37 CORS sites throughout country. The network known as PositioNZ mainly is to monitor the country official datum, New Zealand Geodetic Datum 2000 (NZGD2000), by measuring the effects of tectonic plate motion and earthquake displacements.

The New Zealand Government and LINZ have a policy of opening up government data and making it available for free under an open license. LINZ publishes two types of GNSS data from the PositioNZ; static data and real-time data. The real-time data is streamed via the internet to users in the field to allow for accurate positioning in real-time. Both type of data are utilized for surveying, construction, scientific applications and etc. The static data is provided in an open format which allows the data to be used with many different GNSS receiver brands and models. The real-time (PositioNZ-RT) service also provides GNSS data in an open format designed for streaming data via the internet. Both datasets are licensed for re-use under the CCBY 4.0 NZ license. Several private CORS operators use this data to supplement their private networks. The GNSS community can benefit from this open and freely available data. 


\section{Australia}

The Australia's government has no investment in the GNSS upstream satellite program at the current stage or coming future. The country has setup ground infrastructure and operate high positioning service to support a wide range of sectors and industries. Several initiatives have been taken in this regard to oversee the national GNSS infrastructure development as well as to support the acquisition, processing, distribution and extending user access of multi-GNSS data. Among them are the Spatial Information Council's (ANZLIC) implementation of the National Positioning Infrastructure Policy, the Australian Spatial Consortium's (ASC) Strategic Plan for GNSS, and Geoscience Australia's National Infrastructure Plan (NPI). The NPI will improve and enhance the existing CORS infrastructure, governance and data sharing arrangements (Queensland Foundation Spatial Data Framework, 2018).

In Australia, the Federal, State and Territory governments are responsible for funding and managing CORS sites as part of their positioning infrastructure. Each jurisdiction has a significant degree of autonomy in developing spatial policies that articulate roles and responsibilities for deploying, accessing and managing CORS infrastructure and broader positioning frameworks (Hale, 2007). As a result, the CORS infrastructure investment by State and Territory governments has been found to be inconsistent and primarily influenced by regional commercial incentives.

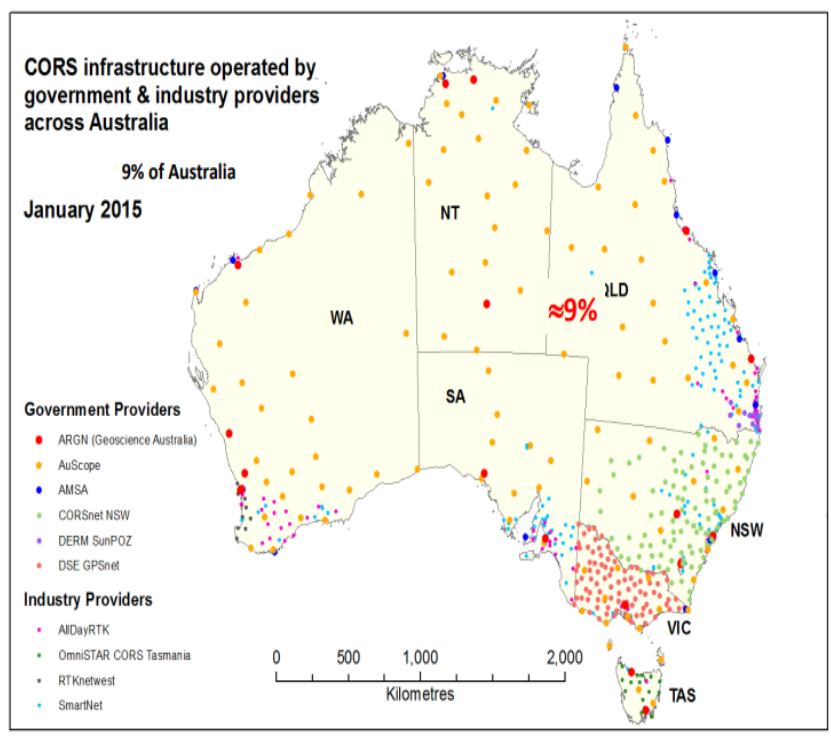

Figure 1: The CORS as at 2015 in Australia Operated By Government And Industry (source: Grant Hausler, Geoscience Australia, 2015)

The industry service providers support in running the CORS network such as SmartNet Aus (150 CORS), AllDayRTK, RTKnetwest (24 CORS), OmniSTAR CORS Tasmania (17 CORS) and Global CORS. They obtain license source raw data from government or third party data providers and market their own value-added positioning services, as well as deploy additional sites in region of high demand. Figure 1 compares the location of CORS provided by data custodians from government and industry. However, data custodians have no obligation to publish the locations of their infrastructure, meaning a large amount of privately owned singlebase infrastructure remains unidentified. 


\section{Continent of Africa}

DOI: 10.35631/JISTM.624024

The development of CORS networks in Africa is being driven by a continental initiative known as the African Geodetic Reference Frame (AFREF). The initiative encourages African governments to modernize their geodetic networks by utilizing modern GNSS technologies through their national mapping agencies. According to Derrick (2019), only a few African countries have been successful in establishing and maintaining national CORS networks. Most other countries have either none or little infrastructure, but it is difficult to know whether it is being used and functioning properly because no information is publicly available.

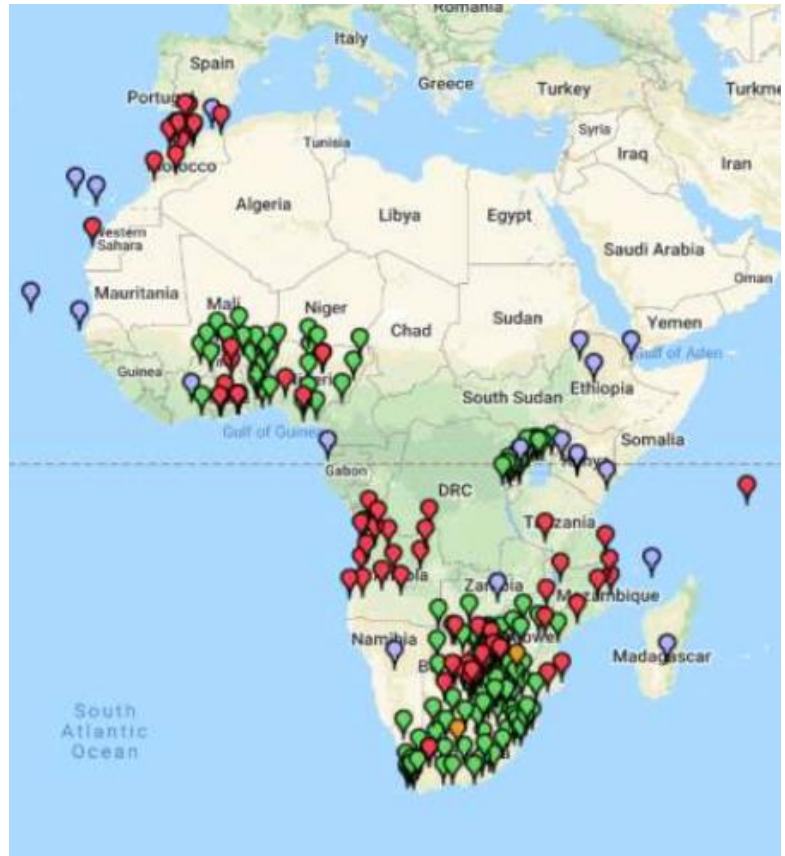

Figure 2. The Current State of Corsmap as of 31 January 2019 (source: Derrick K., 2019)

As of now, more than 100 CORS sites have been installed by government and private organizations across the African continent, including 3 CORS in Kenya, 55 CORS in South Africa (Trignet), 55 CORS in Botswana (Botswana Net), 15 CORS in Nigeria (NINGET), and 8 CORS in Rwanda (Geonet), and etc. This entails establishing a network of CORS that will provide a variety of services, with users from all over Africa having access to the generated data. Meanwhile, the Figure 2 showed the CORSMAP application was developed to compile and maintain a database of all available CORS infrastructure in Africa, and to make it available as a web map that can be accessed freely online. The work is being done to promote AFREF project. Apart from that, CORSMAP is slowly putting together a centralized database that will include all of Africa's CORS installations as well as raw data. In terms of data security, however, CORSMAP does not provide coordinates to any of the stations, instead providing a link to the station provider, and allowing such information to be obtained only from the station custodian. 


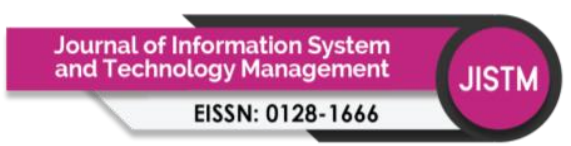

Volume 6 Issue 24 (December 2021) PP. 254-264 DOI: 10.35631/JISTM.624024

\section{Continent of Asia}

\section{China}

The China's first CORS was the Shenzhen CORS or SZCORS established in 2003 by the local government of Shenzhen. It includes five sites and provides positioning services in $3 \mathrm{~cm}$ on horizontal and $5 \mathrm{~cm}$ on vertical. Since then Beijing, Tianjin, Shanghai, Chengdu, Chongqing, Kunming, Wuhan, Hong Kong and some other cities also established CORS (Qiong W, 2015). The National GNSS/BDS CORS service is a Ground Based Augmentation System (GBAS) that covers the Chinese mainland. It offers RTK services, while at the same time, a private service provider developed the commercial Location Based Service (LBS) (Yamin D, 2016). The National GNSS data center (DC) was established to manage GNSS/BDS data from all CORS stations and to broadcast the national wide area CORS service. The primary DC is located at the National Geomatics Center of China (NGCC) in Beijing, and the backup DC is located at the Geodetic data processing center in Xi'an. The Analysis Centre located in Chinese academy of surveying and mapping. The Chinese government intends to expand the GNSS/BDS CORS to the Asia Pacific region, enabling data sharing and collaborative data analysis with other countries. It is also capable of developing CORS service devices, as well as signal design and service standards.

\section{Japan}

In Japan, the Geospatial Information Authority of Japan (GSI), a subordinate agency of the Ministry of Land, Infrastructure, Transport, and Tourism has been in charge of establishing the CORS network known as GEONET since 1994. It is used in Japan to monitor crustal deformations as well as for precise surveying and geodetic frame. GSI enables free access to GEONET data, and selected sites are equipped with resources to enable single-based RTK service. The government of Japan intended to promote precise positioning services and the CORS network could be operated in an integrated manner with ASEAN country, as well as the correction information could be made available to the private sector. In this regards, the Act on the Advancement of Utilizing Geospatial Information (AUGI): 3rd Basic Plan was introduced on March 2017 with the aims to create new industries and services through the high accurate and value-added geospatial information data. The country believes that this is in line with technological innovations such as IoT, big data and AI.

\section{Thailand}

Generally, more than 20 organizations in Thailand are involved in geospatial data and mapping related activities. There are at least 9 organizations, including 3 universities are involved in setup of GNSS CORS ground infrastructures with their own purposes. Meanwhile, Thailand is enhancing its positioning infrastructure known as National CORS Data Centre (NCDC), in order to support the Thailand 4.0 initiative. The National Geo-Information Committee (NCGI) was formed to manage the national geo-information infrastructure and geospatial data. This committee chaired by Prime Minister was tasked with imposing geospatial data, remote sensing standards, and services in order to reduce duplication, improve data sharing, and integrate the information that would be exchanged. Meanwhile, the government had finalized a singlewindow policy for international cooperation on the use of the CORS network in the country with the Royal Thai Survey Department overseeing international cooperation coordination among operating agencies (R. Shibasaki et al, 2018). 
In addition, the Geo-informatics and Space Technology Development Agency (GISTDA) is drafting a roadmap for GNSS CORS Data services administration and management. The roadmap covered a number of activities, which consist of the establishment of a clearlydirected policy on GNSS CORS Data Center and framework for data sharing and services, and providing CORS standards for installations and operational in order to enable interoperating between all stakeholders for more effective and efficiently. On top of that, the document also discussed the promotion of the use of CORS data for driving economic by making the CORS data accessible and available to all sectors and users for application development (Tatiya et.al, 2018).

\section{Malaysia}

In Malaysia, there are few CORS networks currently in services, such as the Department of Survey and Mapping Malaysia (JUPEM), which operates the MyRTKnet primarily for the surveying profession; the Marine Department, which operates a MSK-DGPS to support marine navigation; the National R\&D CORS (NRC-net) which was established by university, government agencies and private sector to support local R\&D activities; as well as the Land and Survey Sabah and Sarawak are in the midst to setup a new CORS to support the state's cadastral and mapping works. Local users mostly are license access to CORS data services for positioning and navigation applications. However, this CORS networks are not unified and the data observation is not centralized to provide standard services. It might led an indirect impact on the opportunity to develop new GNSS downstream applications particularly that involving real-time data.

Apart from that, there are only few studies on the policy or regulatory framework for GNSS development and data in the country, such as The Arahan Keselamatan Terhadap Dokumen Geospatial Terperingkat (AGKT) document classifies the different forms of geospatial data, the National Space Policy 2030 (NSP2030) with the objective to the development of space technology, infrastructure and applications in three main space sectors that including PNT or GNSS.

\section{Discussion}

CORS networks and data have been used worldwide to meet the scientific and commercial demands from multiple sectors. The operational models of the CORS network differed by country. The majority of developed countries, including Europe, the United States, and Australia are involving the private sector to operate the CORS infrastructure. The government makes its data available to industry service providers so that they are able to market their own value-added positioning services to the general public. This has benefited the industry by allowing them to play an important role in national positioning services, as well as ensuring the sustainable development of GNSS sector in the country. In addition, data licensing model allows multiple service providers to access the same CORS infrastructure. It could avoid duplication over-investment and burden of managing the CORS infrastructure development in the country.

The New Zealand's government takes the open data policy and release data free of charge under an open license. Several private CORS service provider use this data to supplement their private networks. In return, they willing to provide data from their network to the government, which is used to improve the national datum and also support critical applications such as 
earthquake response and recovery works. Being willing to share data openly brings benefits to many GNSS community.

In some countries where the CORS is operated by multiple government agencies, such as in Australia. There are a few technical issues that need to be addressed, including the data observation is not centralized and thus unable to provide standard services with limited quality control; the data being dominated by a single agency, and restricting data access and sharing for public and industrial positioning applications. Apart from that, each organization's role in operating CORS need to be clearly defined in order to avoid authority conflicts and put in place an effective coordination mechanism. In this regards, Higgins (2008) was identified model for understanding organizational roles in managing the CORS network to delivery of precise positioning services.

\begin{tabular}{|c|c|c|c|c|}
\hline $\begin{array}{l}\text { Specify System } \\
\text { - Target Density, } \\
\text { Coverage } \\
\text { Reliability and } \\
\text { Availability } \\
\text { - Site Quality } \\
\text { - Equipment } \\
\text { Quality } \\
\text { - Geodetic } \\
\text { Reference } \\
\text { Frame } \\
\text { Data Services } \\
\text { Produced } \\
\text { Data Access } \\
\text { Policy }\end{array}$ & $\begin{array}{l}\text { Own Stations } \\
\text { - } \quad \text { Site Selection } \\
\text { - } \quad \text { Site } \\
\text { Construction } \\
\text { - Equipment } \\
\text { Purchasing } \\
\text { - Station Data } \\
\text { Comms } \\
\text { - Site } \\
\text { Maintenance } \\
\text { Equipment } \\
\text { Replacement } \\
\text { Cycle }\end{array}$ & $\begin{array}{l}\text { Network the Data } \\
\text { - Data Comms } \\
\text { from Network } \\
\text { Stations } \\
\text { - Control Centre } \\
\text { - Data Archive }\end{array}$ & $\begin{array}{l}\text { Process Network } \\
\text { - Copy of } \\
\text { Network } \\
\text { - Data } \\
\text { Processing } \\
\text { - Production of } \\
\text { Data Streams } \\
\text { - Distribution of } \\
\text { Data Streams } \\
\text { - Data } \\
\text { Wholesaling } \\
\text { - Retailer } \\
\text { Support }\end{array}$ & $\begin{array}{ll}\text { Deliver Service } \\
\text { - } & \text { Retail Sale of } \\
& \text { Data Products } \\
\text { - } & \text { Marketing } \\
\text { - } & \text { Rover } \\
& \text { Equipment } \\
& \text { support } \\
\text { - } & \text { End User } \\
& \text { Support } \\
\text { - } & \text { Liaison with } \\
& \text { User Comms } \\
& \text { Providers }\end{array}$ \\
\hline
\end{tabular}

\section{Figure 3: A Model For Describing Organizational Roles In Managing GNSS Infrastructure And Precise Positioning Services}

(Source: Higgins M.B. 2008)

As shown in Figure 3, the model is divided into five discrete roles that a specific organization may play, including specific system, station, network, process network, and deliver services. Each of these roles is described in more detail by detailing the types of activities performed in each role. Data access policy is one of the activities covered under specific system which stated as follow:

i. Post processed data at 30 second epochs free for scientific users, as well as for the establishment and maintenance of the national geodetic reference frame;

ii. Single station real time data stream free for scientific user; and

iii. Dual frequency real time GPS/ GLONASS corrections and post processed data at 1 second epochs subject to a fee for commercial users

Clear governance mechanisms (showed in horizontal arrow) are important because they allow all parties involved to understand where they stand in terms of business and legal issues, but they also give confidence to user that the service is reputable and trustworthy. The governance processes are quite simple in situations where one organization plays all of the roles. However, if various organizations play different roles in the delivery of precise positioning services, some Copyright (C) GLOBAL ACADEMIC EXCELLENCE (M) SDN BHD - All rights reserved 
governance processes will be required to support the service, such as agreements between different organizations in different roles clarifying the rights and responsibilities of each party and setting agreed-upon service levels.

\section{International Organizations And Initiatives}

The United Nations recently recognized the importance of geodetic systems as critical infrastructure. In 2017 the UN established a sub-committee on Geodesy to promote better coordination of national geodetic activities, and establish sustainable and accurate Global Geodetic Reference Frames (GGRF). The important factors to facilitate this is the concept of open data and sharing of data between countries (Robert, 2018).

Meanwhile in August 2018, the World Bank and United Nations Committee of Experts on Global Geospatial Information Management (UN-GGIM) collaborated in the development of the Integrated Geospatial Information Framework (IGIF). The Framework presents a forwardlooking approach that creates an enabling environment where national governments can coordinate, develop, strengthen and promote efficient and effective use and sharing of geospatial information for policy formulation, decision-making and innovation. It's designed to help member states to better manage their geospatial information at national or sub-national levels.

In ASEAN country, the CORS networks contribute to high-precision positioning beyond country boundary, particularly in the areas with a low density of reference stations. However, data transfer beyond country borders is another challenging issue. According to Shibasaki R. et al. (2018), ASEAN could consider developing a multilateral agreement on the use of CORS networks among member states. In order to sustain value creation from geospatial data while respecting the rights and concerns of data producers, a specific ASEAN policy directions consisting of the adoption of coordinated data policy for advanced usage, and be focused as below:

i. Ensuring a smoother flow of data and a clearer responsibility for data usage;

ii. Sharing the benefits of value creation from data amongst data producers and value creators;

iii. Monitoring and assessing the risks and benefits of data usage and data market competition in a coherent manner;

iv. Accelerating human resource development for value creation.

\section{Conclusions}

GNSS or CORS data provide a wide range of benefits. The data should be shared and made accessible with minimum restrictions in order to realize and optimize these benefits. It is also important that users contribute to the system by providing open and sharing data to improve the system of applications. Through sharing of data as well, it will promote creativity, broaden the use of the data, and assists help solve many of the global issues and natural disasters that affected people. Data sharing should also consider international principles, whereas the data is complete and comprehensive; timely, useable and accessible; interoperable; machine readable and operable; non-discriminatory; non-proprietary; and available under an open license or agreement (Robert, 2018).

The goal of this study is to develop a clear conceptual framework for GNSS and CORS data sharing and operational practice in the country. Currently, the AGKT document is in place to 


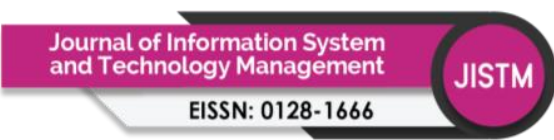

Volume 6 Issue 24 (December 2021) PP. 254-264 DOI: 10.35631/JISTM.624024

classify different forms of geospatial data. In order to resolve some grey areas between public and private GNSS users, the country probably requires a data sharing strategy. Aside from that, GNSS is now contributing to Big Data by combining PNT information with other technologies, and it can be considered as fundamental element of Industry 4.0 due to its ability to improve current technological advancements. With the model framework, it could be optimised the benefits of GNSS and it may result in continuous of government support to the GNSS programme and development.

\section{References}

Bruyninx, C. et.al. (2019). GNSS Metadata and Data Validation in the EUREF Permanent Network, GPS Solutions, Volume 23, number: 106.

Derrick, K., Clement, O. and Eldar, R. (2019). Developing Africa one CORS at a Time. In FIG Working Week, Geospatial information for a smarter life and environmental resilience.

Grant, J.H. (2014), National Positioning Infrastructure: Technical, Institutional and Economic criteria for coordinating access to Australia's GNSS CORS Infrastructure, PhD Thesis. University of Melbourne.

Higgins, M.B. (2018). An organisational model for a unified GNSS reference station network for Australia. In Journal of Spatial Science, 53:2, pp 81-95.

Katsuhiro, N. et al. (2017). Basic Plan for the Advancement of Utilizing Geospatial Information (2017). Japan.

Mikael, L., Peter, W. and Gunnar, H. (2014). The Use of GNSS in Sweden and the National CORS Network SWEPOS. In proceedings FIG Congress.

Mikael, L. (2017). Data Sharing in Europe. In proceedings Regional Challenges, Benefits and Opportunities of Exchanging Geodetic Data.

NGS Geodesy - CORS, US National Geodetic Survey (2018) http://geodesy.noa.gov.

Ordnance Survey, OS Net, Ordnance Survey, viewed 15 April 2021. http:// www.ordnancesurvey.co.uk

Qiong, W., Jingyu, K., Shuwen, Li., Jianing, Z. and Hongqing, L. (2015). GNSS Positioning by CORS and EGM2008 in Jilin Province, China. In Sensors, 30419-30428.

Queensland Foundation Spatial Data Framework SIG/2016/3332 (2018). Department of Natural Resources, Mines and Energy.

Robert, S. and Graeme, B. (2018). The social, technical, environmental and economic benefits and opportunities of accessing and sharing geodetic data. in FIG Congress.

Shibasaki, R, Fukuyo.T., Miyazalo, H., Verspieren, Q. and Anbumozhi, V. (2018). Integrated Spaced-Based Geospatial System: Strengthening ASEAN's Resilience and Connectivity. Economic Research Institute for ASEAN and East Asia, National Library of Indonesia Cataloguing-in-Publication Data, Jakarta, 2018), pp 45-51.

Tatiya, C., Chuthamart, P. and Duranee, P. (2017). Status of Thailand's Geospatial Data Infrastructure and Systems. PowerPoint, Geo-informatics Products Office, GISTDA, Secretariat Team of National Committee on Geo-information.

Vimalachandran et.al. (2019). Lost in GNSS: A need for commercial space policy for positioning, navigation and timing. Aeronautics and Aerospace Open Access Journal, (2019), pp 134-138

Yamin, D. (2016). National GNSS/BDS CORS Services in China. In proceedings FIG Conference. 